\title{
ESTUDO COMPARATIVO DE TRATAMENTO BIOLÓGICO E FOTOCATALISE HETEROGÊNEA PARA A REDUÇÃO DE COR E DQO DE EFLUENTE DE FÁBRICA DE CELULOSE E PAPEL INTEGRADA
}

Valdir de Oliveira

Robson José Martussi

Rubiane Ganascim Marques

RESUMO: O efluente de celulose e papel é um efluente que apresenta uma elevada carga orgânica e coloração. Atualmente seu tratamento é realizado por uma série de etapas que abrange tratamentos primários, secundários e terciários. O presente trabalho teve como objetivo comparar a eficiência do tratamento biológico e da fotocatálise para redução de cor e de demanda química de oxigênio em efluente de celulose e papel. Observou-se que a fotocatálise heterogênea apresentou um melhor desempenho que 0 tratamento biológico, mas mesmo assim não se conseguiu enquadrar o efluente dentro dos parâmetros de demanda química de oxigênio da legislação.

Palavras-chave: Fotocatálise heterogênea. Tratamento biológico. Efluente de celulose e papel. 


\section{INTRODUÇÃO}

A indústria de celulose e papel tem um alto potencial poluidor. De acordo com Ali e Sreekrishnan (2001), este setor foi considerado o sexto maior potencial poluidor em 2001, com grandes fontes de poluição do ar e dos recursos hídricos.

O efluente líquido gerado na indústria de celulose e papel contém uma grande variedade de matéria orgânica, a qual apresenta: baixa biodegradabilidade, alta coloração, compostos orgânicos halogenados adsorvíveis (AOX) e toxicidade elevada (YEBER et al., 2000; KO et al., 2009). O principal constituinte desse efluente são fragmentos de lignina e sais inorgânicos, como sulfatos e cloretos (MACHADO et al., 2003). O setor de celulose e papel apresenta uma qualidade de efluente bruto de característica acentuada quanto aos seus parâmetros macros, em função dos processos empregados pelas principais empresas brasileiras. Mesmo com a diversificação dos produtos e processos do setor de celulose e papel, os sistemas e tecnologias empregados não apresentam uma grande variabilidade e os resultados obtidos atendem a legislação brasileira, chegando a alguns casos a superá-la.

O tratamento de efluente gerado na indústria de celulose e papel integrado pode ser dividido em três etapas: tratamento primário, tratamento secundário e tratamento terciário.

O tratamento primário é constituído unicamente de processos físico-químicos. Nesta etapa de tratamento ocorre a retirada de material grosseiro e particulado. $\mathrm{O}$ tratamento secundário é a etapa na qual ocorre a remoção da matéria orgânica, por meio de reações bioquímicas. E o tratamento terciário consiste de técnicas avançadas de tratamento de efluentes (BRAGA, 2005).

Na figura 1 pode-se observar uma estação de tratamento de efluentes típica de uma industria de celulose e papel. 


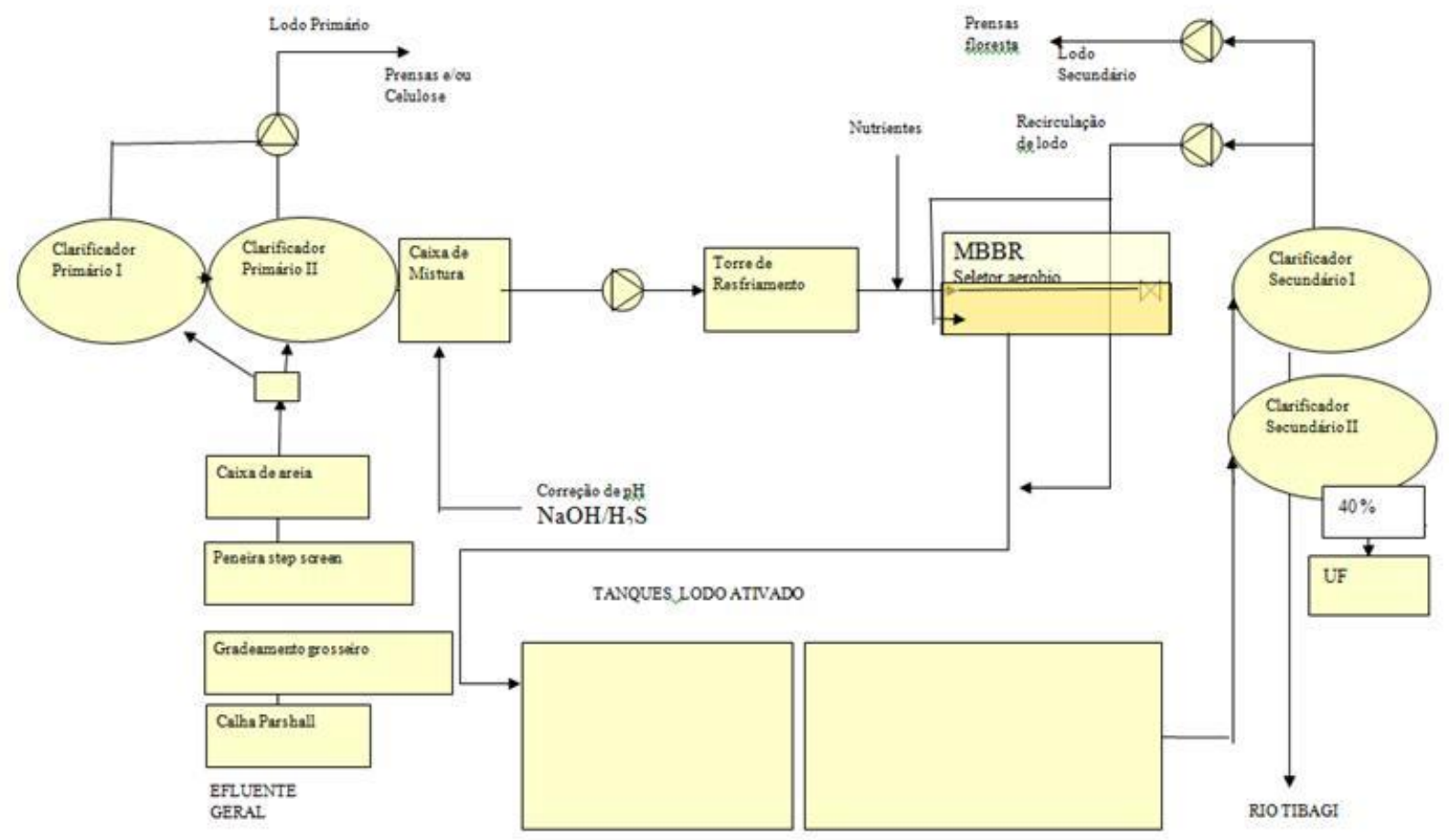

Figura1. Planta típica de tratamento de efluente de uma indústria de celulose e papel.

(fonte: autor)

O presente trabalho tem como objetivo comparar o tratamento biológico através de lodo ativado com o tratamento terciário de fotocatálise heterogênea.

\section{MATERIAIS E MÉTODOS}

O efluente e o lodo utilizados nos experimentos foram cedidos pela indústria Klabin S/A unidade Monte Alegre. O efluente foi coletado antes de seguir para o tratamento biológico de efluentes. O lodo utilizado no experimento foi coletado no reciclo dos decantadores biológicos.

O fotocatalisador utilizado foi o dióxido de titânio Aeroxide® P25 cedido pela empresa Evonik.

2.1- Tratamento biológico. 
Foi realizada uma simulação em laboratório de um tanque de lodo ativado com tratamento por batelada.

A figura 2 apresenta o reator laboratorial para o tratamento biológico.
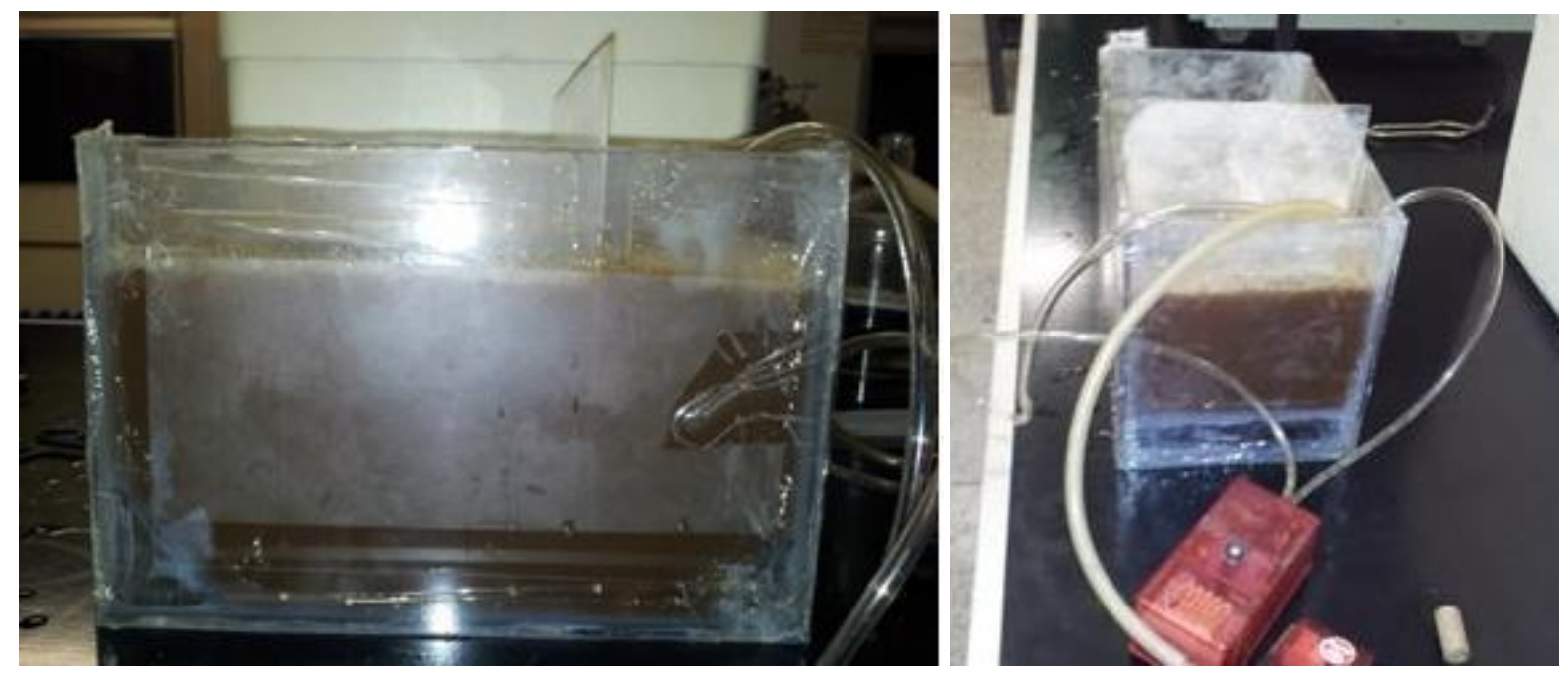

Figura 2. Vista frontal e lateral do biorreator com lodo ativado.

O biorreator tem um volume total de 10 litros, mas para a reação foi utilizado 4 litros de efluente e 3 litros de lodo ativo, esta quantidade foi realizada tomando base a relação de efluente e lodo ativado utilizado no tratamento biológico industrial. O tempo reacional foi de 2 horas com aeração distribuída pelo reator através de duas bombas de insuflar oxigênio em aquário.

Ao final da reação foi coletada amostra de lodo para analise de microscopia para identificação dos microrganismos existentes no mesmo.

A eficiência do tratamento de efluentes foi analisada pela redução de Demanda Química de Oxigênio (DQO) e Cor.

\subsection{Fotocatálise Heterogênea.}

A metodologia empregada foi a mesma de Ferrari (2010) e Marques (2005). Como catalisadores o dióxido de titânio Aeroxide® P25. A unidade reacional consistiu em um 
béquer de vidro de $1000 \mathrm{~mL}$, com sistema de agitação magnética, lâmpada com potência de $250 \mathrm{~W}$ (General Eletric) sem o bulbo de vidro protetor e caixa protetora para impedir a passagem da luz UV, conforme mostrado na Figura 3.

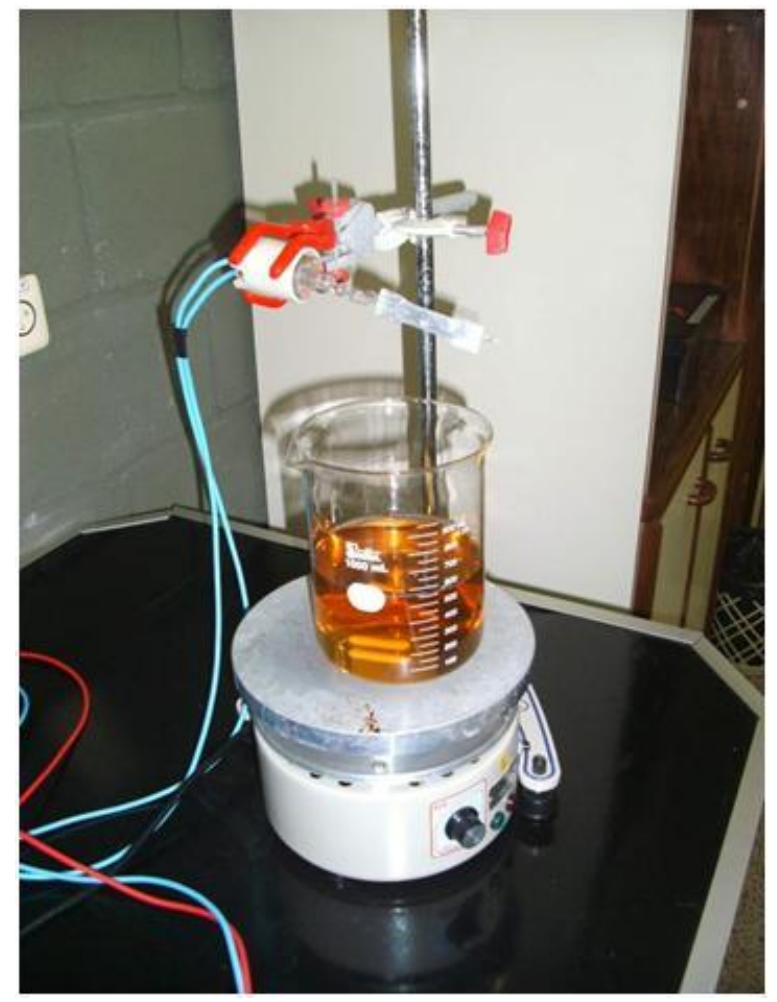

Figura 3. Fotoreator

Os testes fotocatalíticos foram realizados na unidade reacional em batelada (Figura 2), por $2 \mathrm{~h}$, à temperatura ambiente, com uma concentração de catalisador de $1 \mathrm{~g} / \mathrm{L}$, contendo $500 \mathrm{~mL}$ de efluente, sob agitação magnética e irradiação de luz, sem aeração.

A eficiência do tratamento de efluentes foi analisada pela redução de DQO e Cor.

\section{RESULTADOS E DISCUSSÕES}

Inicialmente foi feita a caracterização do efluente coletado, este apresentou uma DQO inicial de $617 \mathrm{mg} / \mathrm{L}$ e uma cor de 1670ppm de cobalto-platina. 
Durante o experimento de lodo ativado observou-se o crescimento do mesmo, o que levou a redução da DQO e a coloração do efluente. A DQO final foi de $414,5 \mathrm{mg} / \mathrm{L}$ e da cor foi de 1670 ppm de co-pt.
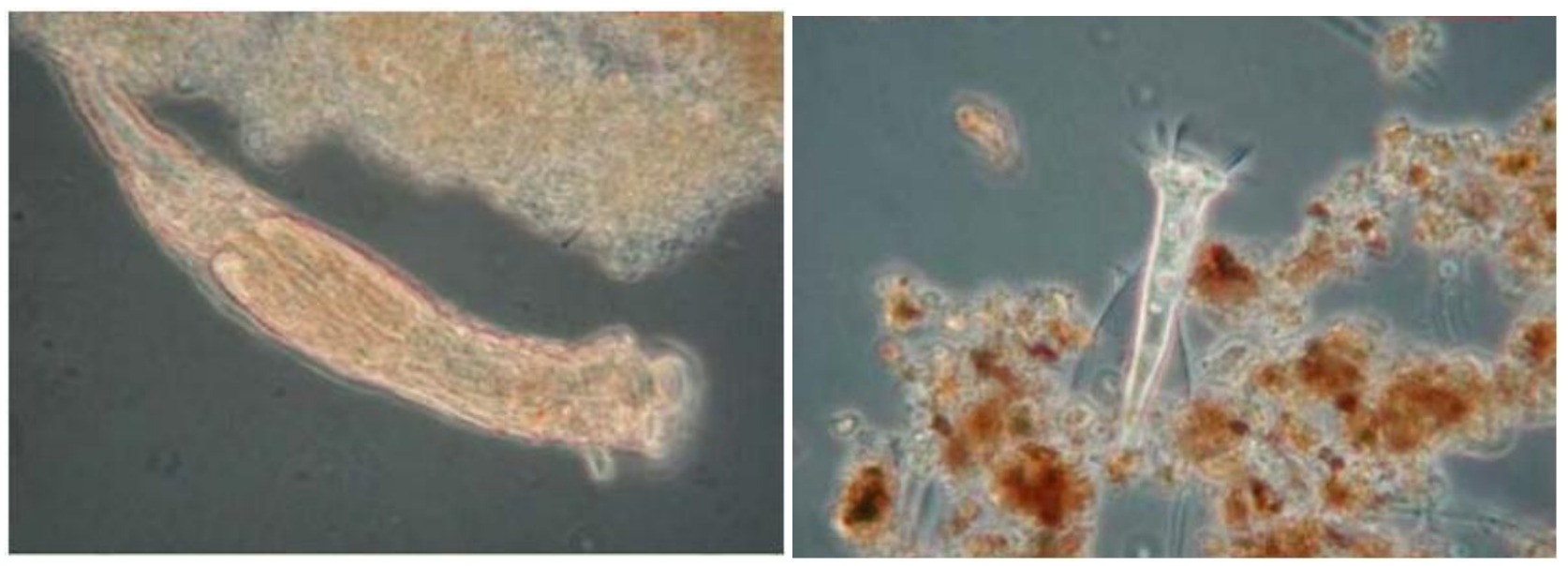

Figura 4. Alguns dos microrganismos encontrado no Lodo Ativado.

Ao final do experimento foi feita uma lamina do lodo do bioreator, neste ensaio de microscopia foi encontrado diversos tipos de protozoários, na figura 4 observa-se as espécies de Rotífero e Vorticella os quais indicam uma boa qualidade do lodo pois eles só se desenvolvem quando as características deste efluente esta adequado com boa oxigenação e baixa toxicidade.

No teste fotocatalítico a demanda química de oxigênio obtida após 2 horas de teste foi de $322 \mathrm{mg} / \mathrm{L}$ e a cor reduziu para 1578 ppm de co-pt.

A eficiência dos processos pode ser observada na Figura 5. 


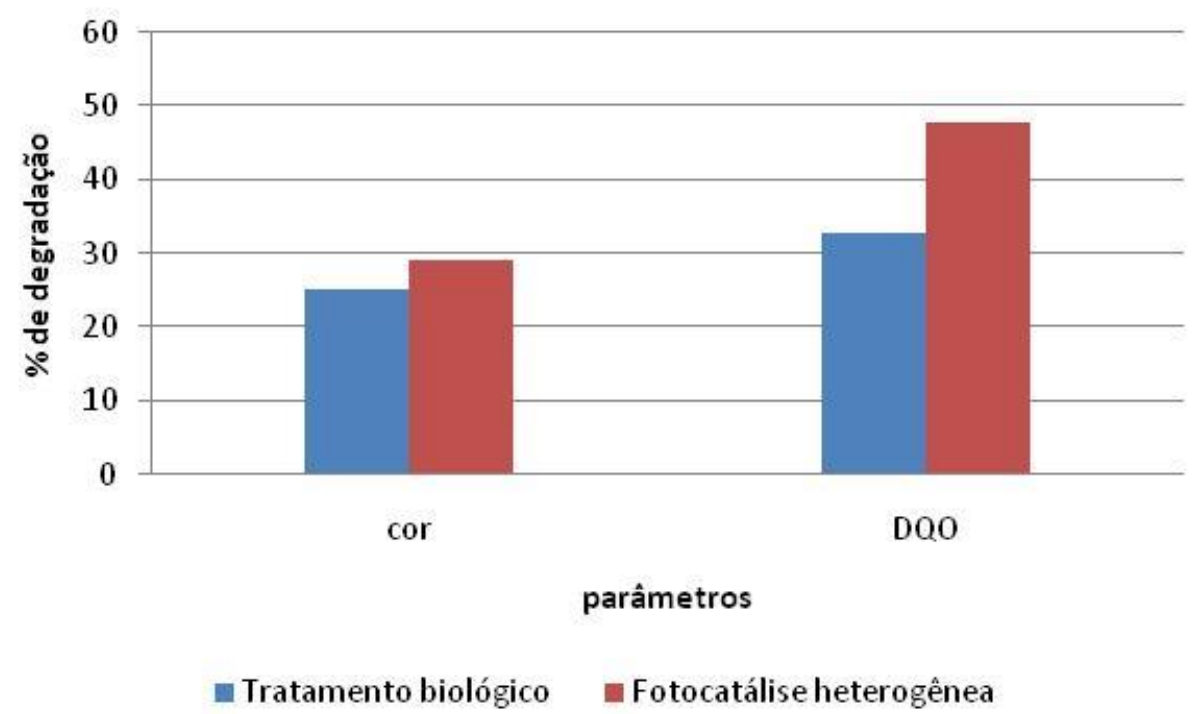

Figura 5. Comparação entre os tratamentos fotocatalíticos e biológicos de um efluente de celulose e papel.

Observa-se na Figura 5, que a fotocatalise heterogênea foi mais eficiente tanto para a remoção de cor quanto para redução de DQO do efluente industrial.

Apesar de ambos os casos ter ocorrido a degradação, o efluente estudado é lançando em um rio pertencente à classe "1",segundo resolução 357 do CONAMA, 2005 (http://www.recursoshidricos.pr.gov.br). O padrão de lançamento de DQO das indústrias de celulose e papel, segundo normativa do IAP e resolução do CONAMA 2005, é de 260mg/L aproximadamente. Então o efluente não encontra-se enquadrado para lançamento no corpo receptor, necessitando assim de um maior tempo reacional em ambos os casos para adequação da demanda química de oxigênio.

Em relação a coloração do rio, como a legislação não tem uma especificação padrão, o efluente poderia ser descartado no rio.

\section{CONCLUSÕES}




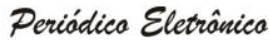

O efluente da indústria de celulose e papel é um efluente que apresenta uma elevada carga orgânica com uma DQO de $617 \mathrm{mg} / \mathrm{L}$ e uma coloração de 2230ppm de copt.

No tratamento biológico foi obtido uma redução de $25 \%$ de cor e de $33 \%$ de demanda química de oxigênio. No lodo ativado foram identificadas as espécies de Rotiferos e Vorticella.

No tratamento fotocatalítico foi alcançada uma redução de $29 \%$ de cor e de $48 \%$ de DQO, mostrando este ter uma eficiência maior que o tratamento biológico.

Em ambos os tratamentos não foram alcançados os padrões legais para o tratamento de efluente, então faz-se necessários mais estudos para alcançar os mesmos.

\section{REFERÊNCIAS}

ALI,M., SREEKRISHNAN, T.R.,"Aquatic toxicity from pulp and paper mill effluents: a review", Advances in Environmental Research, v. 5, pp 175-196, 2001.

BRAGA, B. Introdução à Engenharia Ambiental, 2º ed - São Paulo, 2005.

FERRARI, A.M.C.C. Tratamento de Efluente de Terminal de Combustível: Coagulação/Floculação/Fotocatálise, Dissertação de mestrado, Universidade Estadual de Maringá, 2011.

KO, C.H., HSIEH, P.H., CHANG, M.W., CHERN, J.M., CHIANG, S.M., TZENG, C.J., "Kinetcs of pulp Mill effluent treatment by ozone-basead process", Jounal of Hazardous Materials, v.168, pp. 875-881, 2009.

MACHADO, A.E.H., MIRANDA, J.A., FREITAS, R.F., DUARTE, E.T.F.M., FERREIRA, L.F., ALBUQUERQUE, Y.D.T., RUGGIERO, R., SATTLER, C., OLIVEIRA, L., , "Destruiction of the organic matter present in effluent from a cellulose and paper industry using photocatalysis", Journal of Photochemistry and Photobiology A: Chemistry 155, pp 232-241, 2003.

MARQUES, R. G. Decomposição Fotocatalítica de Gasolina Sintética e Comercial. Dissertação de mestrado. Universidade Estadual de Maringá, Maringá - PR, 2005.

YEBER, M.C.,RODRÍGUEZ, J., FREER, J. DURAN, N., MANSILLA, H.D., 2000, "Photocatalytic degradation off cellulose bleaching effluent by supported $\mathrm{TiO}_{2}$ and ZnO", Chemosphere, 41, 1193-1197. 